\title{
A 3D Follow-Up Study of Cranial Asymmetry from Early Infancy to Toddler Age after Preterm versus Term Birth
}

\author{
Anniina M. Launonen ${ }^{1,2,3, *,+}$, Henri Aarnivala ${ }^{3,4,5,+}$, Panagiotis Kyteas ${ }^{6}$, Ville Vuollo ${ }^{1,2,3}$ (D), \\ Tuomo Heikkinen ${ }^{1,2,3} \mathbb{D}^{\text {, }}$, Chung H. Kau ${ }^{6} \mathbb{D}^{-}$, Pertti Pirttiniemi 1,2,3, Virpi Harila 1,2,3 \\ and A. Marita Valkama ${ }^{3,4,5}$ iD \\ 1 Department of Oral Development and Orthodontics, Oulu University Hospital, Oulu, Finland; \\ ville.vuollo@oulu.fi (V.V.); tuomo.heikkinen@oulu.fi (T.H.); pertti.pirttiniemi@oulu.fi (P.P.); \\ virpi.harila@oulu.fi (V.H.) \\ 2 Department of Oral Development and Orthodontics, Unit of Oral Health Sciences, Faculty of Medicine, \\ University of Oulu, Oulu, Finland \\ 3 Medical Research Center Oulu, Oulu, Finland; henri.aarnivala@student.oulu.fi (H.A.); \\ marita.valkama@ppshp.fi (A.M.V.) \\ 4 Department of Children and Adolescents, Oulu University Hospital, Oulu, Finland \\ 5 PEDEGO Research Group, University of Oulu, Oulu, Finland \\ 6 Department of Orthodontics, University of Alabama, Birmingham, AL 35294-0007, USA; \\ panoskyt@uab.edu (P.K.); ckau@uab.edu (C.H.K.) \\ * Correspondence: anniina.launonen@oulu.fi \\ + These authors contributed equally to this work.
}

Received: 12 September 2019; Accepted: 8 October 2019; Published: 11 October 2019

\begin{abstract}
Preterm infants are at higher risk for both symmetrical and asymmetrical head molding. This study involved 3D stereophotogrammetry to assess the cranial growth, molding, and incidence of deformational plagiocephaly (DP) in preterm children compared to term born children. Thirty-four preterm infants and 34 term born controls were enrolled in this study from Oulu University Hospital, Finland. Three-dimensional head images were obtained at the age of 2-4 months (T1), 5-7 months (T2), 11-13 months (T3), and 2.5-3 years (T4) from the term equivalent age (TEA). There was no statistically significant difference in oblique cranial length ratio (OCLR), cephalic index (CI), or weighted asymmetry score (wAS) between the two groups. Occipital flattening, defined by flatness score (FS) was statistically significantly greater in the preterm group than in the term group at T1-T4 $(p<0.05)$. In both groups, OCLR improved gradually over time. There were no instances, in either group, of severe DP and no moderate DP after T2. Results indicate that DP affects preterm and full-term children almost equally during the first three years of life, and cranial asymmetry resolves at a similar rate in both preterm and term groups after three months of corrected age. Preterm infants present with more occipital flattening than full-term children.
\end{abstract}

Keywords: preterm; 3D-imaging; deformational plagiocephaly; cranial growth; oblique cranial length ratio; cephalic index; flatness score; weighted asymmetry score

\section{Introduction}

Deformational plagiocephaly (DP) refers to an asymmetrical head shape resulting from environmental forces on the infant's cranium. Since 1992, the American Academy of Pediatrics (AAP) has recommended that infants sleep in a supine position to prevent sudden infant death syndrome (SIDS). After that, the reported prevalence of DP has risen as high as $46.6 \%$ in Canada [1-3]. However, the reported 
prevalence rates have a wide range, as the prevalence is affected by the evaluation age of the infants, the diagnostic methods used, the decade when the research was performed, and the prevention and follow-up aspects offered by local health professionals [4-11].

The most common visible features in DP are one-sided occipital flattening, forward displacement of the same-sided ear and malar complex, same-sided frontal bossing, and opposite side occipital bossing [11-16]. Frontal DP is uncommon [17]. A hairless bald area on the flattened side of the head, a preferred head position, and a restricted cervical motion are common associated findings.

Because the skullcap of preterm infants (born at a gestational age less than 37 weeks) is very thin and malleable during the early months of life, preterm infants are, according to the literature, at a higher risk for both symmetrical and asymmetrical head molding. The more preterm the infant is, the longer the time from birth to full control of head position; hence, the most immature preterm infants are the most prone to external cranial molding. Cranial narrowing, or dolichocephaly, is commonly described as a typical cranial appearance of very preterm infants, especially at term equivalent age (TEA) $[18,19]$. Additionally, preterm infants go through a long period of hospital care before their discharge home, and if no attention is paid to varying the head position from early on in the neonatal intensive care unit (NICU), preterm infants frequently develop DP [19-21]. If preventive and proactive positioning advice in infant care and handling are provided to the guardians early enough, at least the most severe forms of DP can be prevented in term or near-term newborns infants $[3,7,22,23]$.

The aim of this study was to use 3D stereophotogrammetry to assess cranial molding with a special emphasis on the incidence of plagiocephaly in preterm children in comparison to term born children in early childhood.

\section{Materials and Methods}

\subsection{Study Population and Study Design}

This prospective case-control study was conducted in the Department of Children and Adolescents, Oulu University Hospital, and the Unit of Oral Health Sciences, University of Oulu, Finland. Thirty-four healthy preterm infants (born before 37 completed gestation weeks), and 34 healthy term born controls (born after 37 completed gestation weeks), were enrolled into this follow-up study. There were 11 females and $23(67.6 \%)$ males in each group. The control group was randomly selected from a previously collected nonintervention cohort [8] by computer-based random selection and matched to gender. All participants were born on preselected dates between the years 2012 and 2015 in Oulu University Hospital and entered into the study before their discharge home after birth. Infants were considered eligible if they had no cheilopalatoschisis, craniosynostosis, or dysmorphic features and if they resided within the Oulu region.

Approval for the study was obtained from the ethics committee of the Northern Ostrobothnia Hospital District (Oulu University Hospital; EETTMK 27/2011), and the study complies with the Declaration of Helsinki. The parents of participants authorized study entry by written informed consent. The study was registered with the National Clinical Trials register (NCT02283229).

To reliably compare preterm subjects to term born controls, their ages were computed from the expected date of birth, the term equivalent age (TEA). Subjects attended the study at predetermined time points from the TEA up to the age of 3 years targeted as follows: 2-4 months (T1), 5-7 months (T2), 11-13 months (T3), and 2.5-3 years (T4). At each visit, 3D images of the head were obtained using a 3dMD head 5-pod camera system (3dMD, Atlanta, Georgia, USA). Height, weight, and head circumference measurements were obtained at birth and T1-T4 visits.

\subsection{D Image Analysis}

The 3D images were processed and analyzed with the Rapidform 2006 (Geomagic, Rock Hill, SC, USA) 3D software system using custom macros written with Visual Basic for Applications (VBA). 
More complex mathematical analyses were performed with MATLAB R2014b (MathWorks, Natick, MS, USA).

The point-to-point variables oblique cranial length ratio (OCLR) and cephalic index (CI), as well as the 3D surface variables, weighted asymmetry score (wAS), and flatness score (FS) based on surface normal vector distribution, were measured from the 3D images [24] (Figure 1).

The diagnosis of DP was based on OCLR, with 104\% as the cut-off value for DP, which has been described as the most optimal and clinically relevant cut-off point $[4,25]$. The severity of DP was also categorized based on OCLR: OCLR 104-107.9\% indicates mild; OCLR 108-111.9\% indicates moderate; and OCLR $\geq 112 \%$ indicates severe DP $[5,7]$.
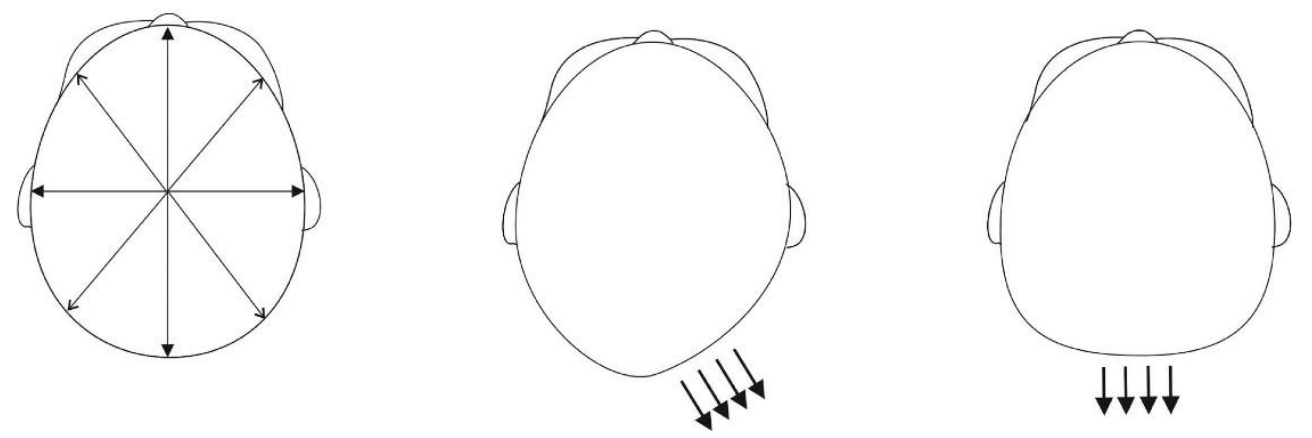

Figure 1. Oblique cranial length ratio $(O C L R$, left figure $)=$ ratio of the longer and shorter transcranial diagonal, measured at a $40^{\circ}$ angle to the midline: (longer diagonal/shorter diagonal) $\times 100 \%$. Cephalic index $(\mathrm{CI}$, left figure $)=$ ratio between the width and length of the head (transversal diameter/sagittal diameter $\times 100 \%$. On a flat surface, surface normal vectors have parallel direction leading to a local maximum in the density function of direction angles. Weighted asymmetry score (wAS, middle figure = an asymmetrical local maximum in the density function, flatness score (FS, right figure) = a symmetrical local maximum in the density function. FS and wAS are calculated by integrating the kernel density estimation function and in wAS, the integrand is multiplied by weight coefficient based on the most posterior point on the occiput.

\subsection{Statistical Analysis}

The normality was assessed using the Shapiro-Wilk normality test. The independent samples $t$-test was used to compare maternal age, gestational age, weight, length, and head circumference between preterm and full-term groups for normally distributed data, and the Mann-Whitney test was used for non-normally distributed data. For outcome variables OCLR, CI, wAS, and FS, the normal distribution of the data could not be verified, so the Mann-Whitney test was used to compare variables between preterm and full-term groups and further between the following subgroups: nonsingletons and singletons, and boys and girls. To compare variables between the subgroups of very preterm (VPT), moderate preterm (MPT), and late preterm (LPT) infants, the Kruskal-Wallis test was used, and Bonferroni corrections were used for post-hoc analyses. The level of significance was set at $p<0.05$. All statistical work and data analyses were conducted using IBM SPSS Statistics version 25.

\section{Results}

Of the 34 preterm and 34 term born infants who participated in this study, two moved away from the area and were unable to visit at T3 and T4. Two preterm infants were unable to show up at $\mathrm{T} 3$ but were able to return at T4. One term born control participant refused to put a stocking cap on at T4, so the images could not be analyzed because of the hair. The mean (SD) corrected ages of preterm versus term born participants were in T1, $3.0(0.8)$ versus $3.6(1.0)$ months $(p=0.012)$; in T2, 6.5 (1.2) versus 6.8 (1.0) months; in T3, 12.9 (1.2) versus 13.3 (0.7) months; and in T4, 3.3 (0.1) versus 3.3 (0.1) years. There were no statistically significant differences in the mean ages of the groups at timepoints T2-T4. 
There were 11 female and 23 (67.6\%) male subjects in each group. All control cases and $14(41.2 \%)$ of the preterm cases were born as singletons. Ten cases of the preterm group were very preterm (VPT, born before 32 completed gestation weeks); 13 were moderate preterm (MPT, born before 34 but more than 32 gestation weeks); and 11 were late preterm (LPT, born between 34 and 37 gestation weeks). Subject characteristics and common growth data are shown in Table 1.

Table 1. Characteristics of study subjects and growth data at birth and at all time points (T1-T4), presented as mean (SD), median, and range values.

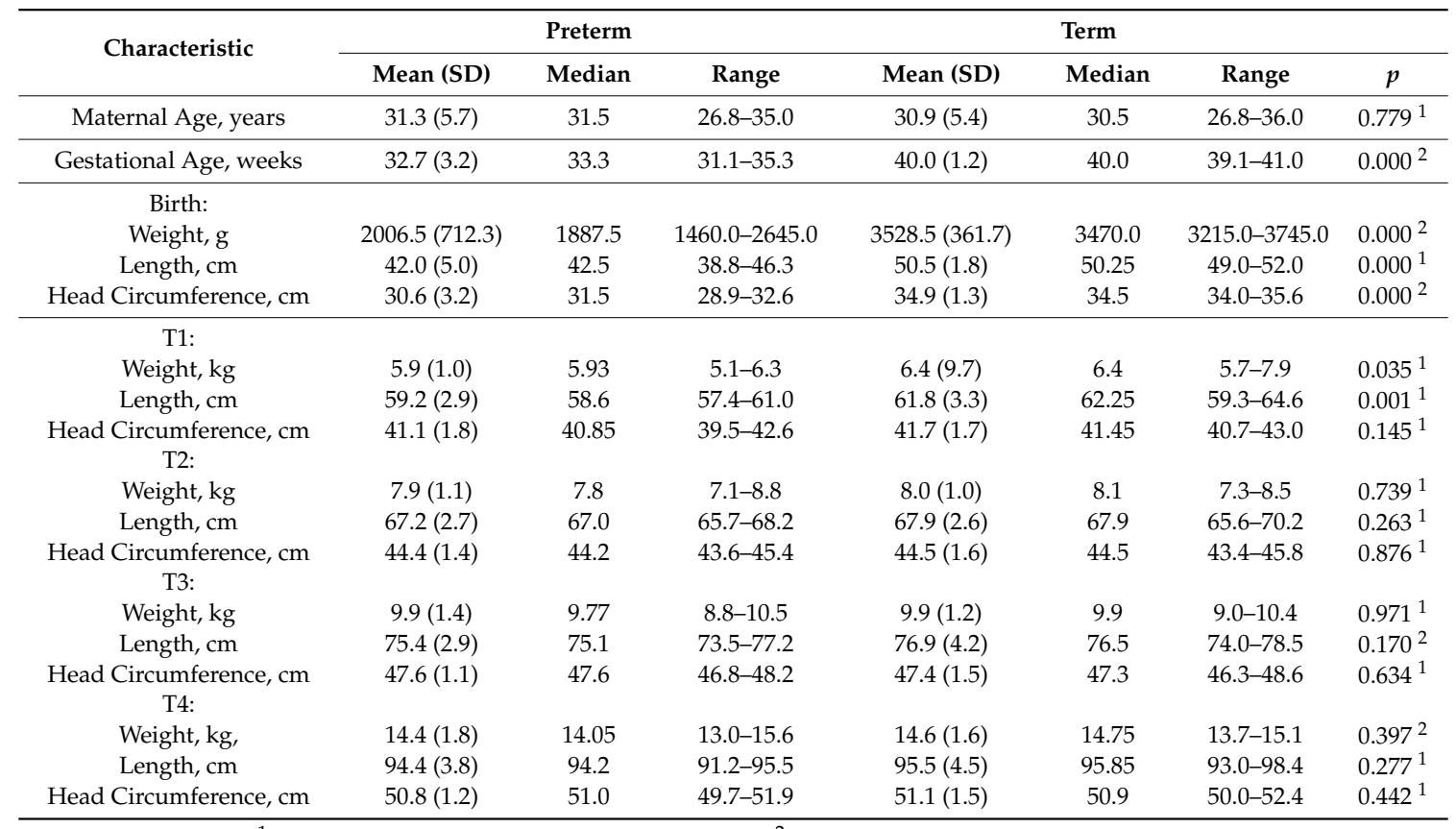

${ }^{1}$ The Independent samples $t$-test was used, ${ }^{2}$ The Mann-Whitney test was used.

As shown in Table 2, no statistically significant difference in OCLR between preterm and full-term children was noted. In both groups, OCLR improved gradually over time (Figure 2). Equally, the number of DP in both groups decreased over time from T1 to T4 (Table 3). There were no severe $\mathrm{DP}$ in either group at any time, and there were no instances of moderate DP after T2. Between the two groups, there was no statistically significant difference in the mean CI. However, the mean FS, indicating occipital flatness, was statistically significantly greater in the preterm group than in the term group in every time point T1-T3 (Table 2).

There were no statistically significant differences in the mean values of OCLR, CI, wAS, or FS between the genders. 
Table 2. The mean (SD), median, and range values for OCLR, CI, wAS, and FS at the study time points (T1-T4) for preterm (PT) and term (T) groups.

\begin{tabular}{|c|c|c|c|c|c|c|c|}
\hline \multirow[t]{2}{*}{$\begin{array}{c}\text { Parameters at T1-T4 } \\
\text { (PT/T, Numbers) }\end{array}$} & \multicolumn{3}{|c|}{ Preterm } & \multicolumn{3}{|c|}{ Term } & \multirow{2}{*}{$\begin{array}{c}\text { Mann-Whitney } \\
p\end{array}$} \\
\hline & Mean (SD) & Median & Range & Mean (SD) & Median & Range & \\
\hline \multicolumn{8}{|l|}{ OCLR \% } \\
\hline $\mathrm{T} 1(34 / 34)$ & $103.7(2.8)$ & 103.1 & $101.1-105.8$ & $103.1(2.3)$ & 102.5 & 101.1-104.6 & 0.425 \\
\hline $\mathrm{T} 2(32 / 34)$ & $102.8(2.3)$ & 102.2 & $101.2-103.7$ & $102.5(2.3)$ & 101.6 & $100.7-104.0$ & 0.330 \\
\hline T3 (30/34) & $102.4(2.0)$ & 101.8 & $100.9-103.5$ & $102.2(1.9)$ & 101.6 & 100.7-103.3 & 0.778 \\
\hline $\mathrm{T} 4(32 / 33)$ & $102.1(1.4)$ & 101.7 & 101.0-103.0 & $102.2(1.7)$ & 101.9 & 100.9-103.3 & 0.958 \\
\hline \multicolumn{8}{|l|}{$\mathrm{CI} \%$} \\
\hline T1 (34/34) & $75.1(5.4)$ & 73.2 & $71.4-78.7$ & $76.9(3.5)$ & 77.1 & $73.6-79.3$ & 0.057 \\
\hline T2 (32/34) & $77.4(6.1)$ & 75.5 & $73.1-80.5$ & $77.6(3.8)$ & 77.4 & $75.5-80.7$ & 0.293 \\
\hline T3 (30/34) & 76.7 (5.7) & 75.6 & $72.8-80.0$ & $76.7(3.3)$ & 76.7 & $75.1-78.5$ & 0.484 \\
\hline $\mathrm{T} 4(32 / 33)$ & $76.4(4.6)$ & 76.0 & $73.2-78.9$ & $76.6(3.1)$ & 76.9 & 73.9-78.0 & 0.529 \\
\hline \multicolumn{8}{|l|}{ wAS } \\
\hline T1 (34/34) & $30.7(36.1)$ & 19.5 & $3.8-45.4$ & $32.7(67.5)$ & 14.2 & $7.6-31.6$ & 0.990 \\
\hline T2 (32/34) & $19.5(24.7)$ & 8.6 & $2.9-24.3$ & $23.9(36.1)$ & 9.1 & $2.8-28.4$ & 0.797 \\
\hline T3 (30/34) & $15.0(15.1)$ & 9.3 & $4.2-21.0$ & $22.1(32.7)$ & 10.2 & $3.5-29.5$ & 0.788 \\
\hline $\mathrm{T} 4(32 / 33)$ & $17.6(21.7)$ & 11.3 & $3.1-24.9$ & $29.0(34.8)$ & 15.6 & $6.5-34.0$ & 0.160 \\
\hline \multicolumn{8}{|l|}{ FS } \\
\hline T1 (34/34) & $0.212(0.019)$ & 0.211 & $0.198-0.225$ & $0.203(0.015)$ & 0.199 & $0.194-0.21$ & 0.030 \\
\hline $\mathrm{T} 2(32 / 34)$ & $0.216(0.022)$ & 0.218 & $0.196-0.229$ & $0.201(0.011)$ & 0.200 & $0.194-0.209$ & 0.003 \\
\hline T3 (30/34) & $0.206(0.018)$ & 0.204 & $0.191-0.218$ & $0.196(0.01)$ & 0.194 & $0.188-0.202$ & 0.037 \\
\hline $\mathrm{T} 4(32 / 33)$ & $0.208(0.016)$ & 0.205 & $0.195-0.224$ & $0.201(0.011)$ & 0.200 & $0.195-0.204$ & 0.081 \\
\hline
\end{tabular}

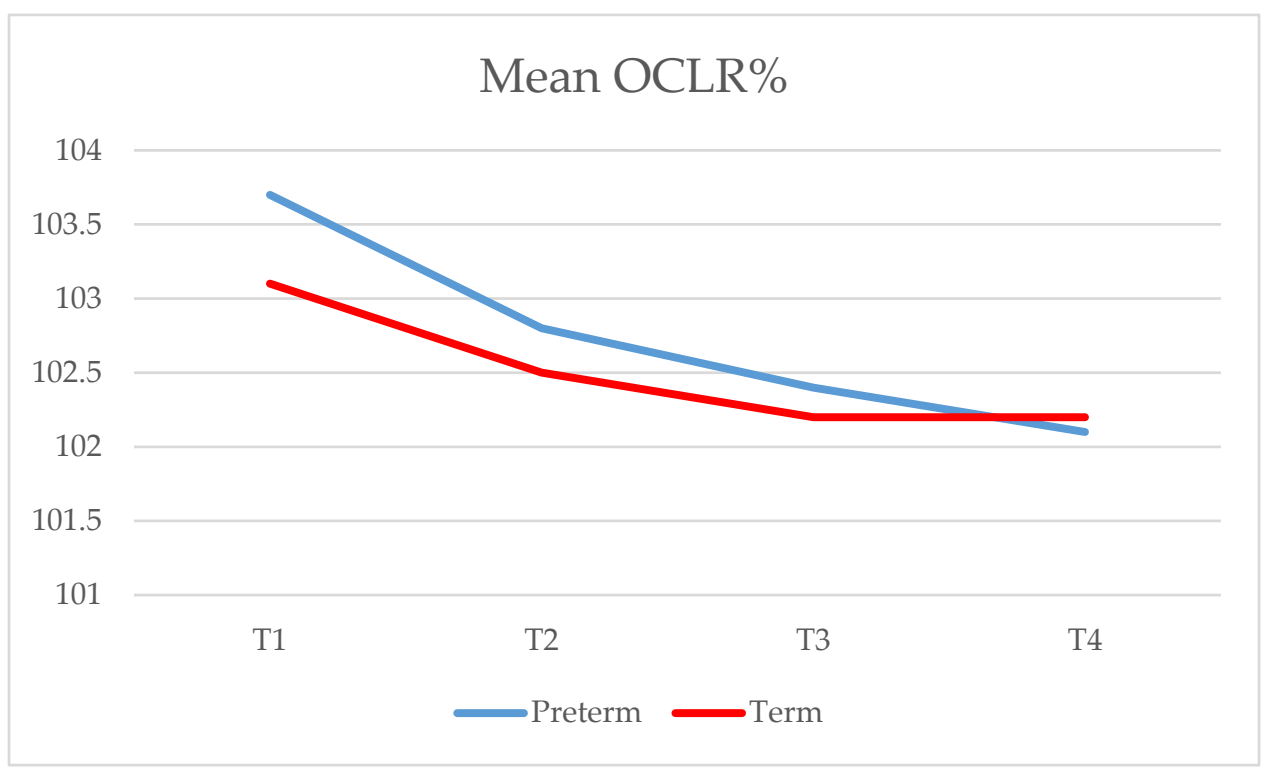

(A)

Figure 2. Cont. 


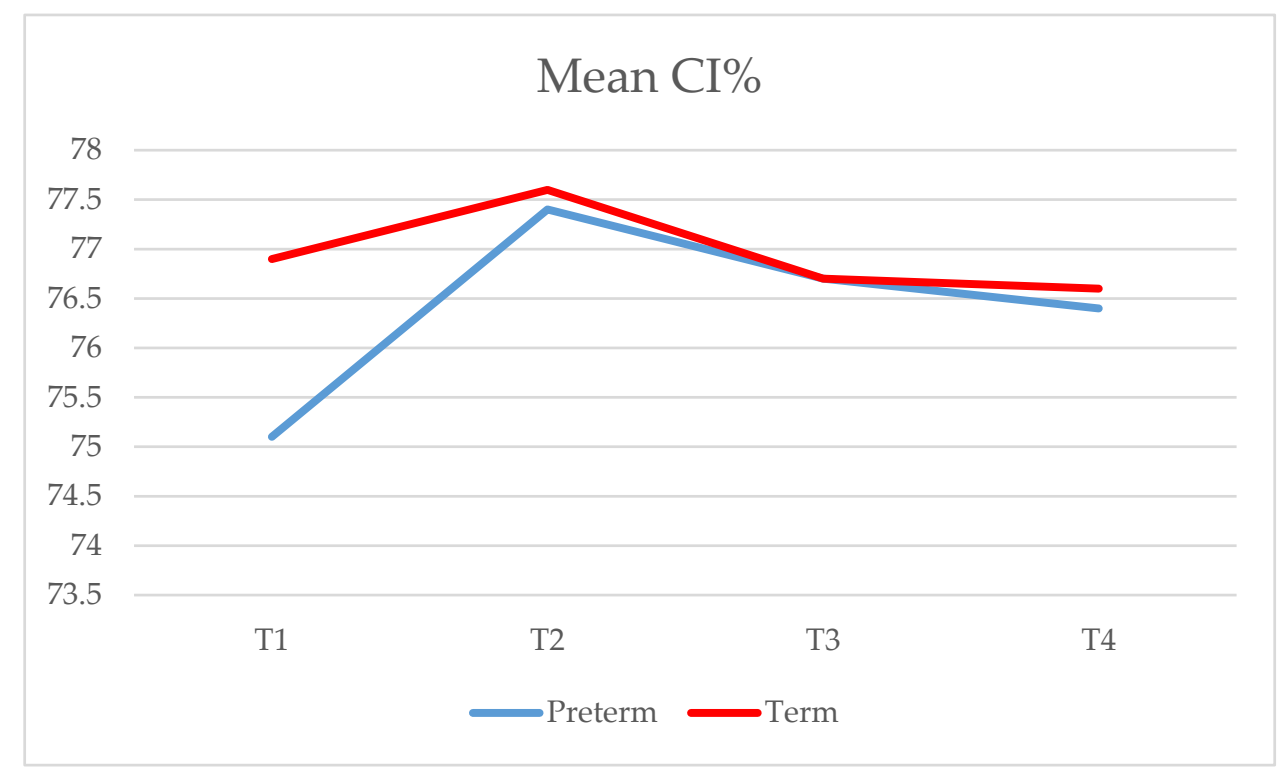

(B)

Figure 2. Mean OCLR\% (A) and CI\% (B) at the study time points (T1-T4) for preterm (PT) and term (T) groups.

Table 3. Number (N (\%)) of preterm and term born subjects with severity levels of deformational plagiocephaly (DP) at timepoints T1-T4.

\begin{tabular}{cccc}
\hline \multirow{2}{*}{ Timepoints } & Severity & Preterm & Term \\
\cline { 3 - 4 } & & $n=34$ & $n=34$ \\
\hline \multirow{2}{*}{ T1 Plagiocephaly } & Total & $13(38.2 \%)$ & $11(32.4 \%)$ \\
& Mild & $10(29.4 \%)$ & $10(29.4 \%)$ \\
& Moderate & $3(8.8 \%)$ & $1(2.9 \%)$ \\
& Severe & 0 & 0 \\
T2 Plagiocephaly & Total & $7(21.9 \%)$ & $8(23.5 \%)$ \\
& Mild & $5(15.6 \%)$ & $7(20.6 \%)$ \\
& Moderate & $2(6.3 \%)$ & $1(2.9 \%)$ \\
& Severe & 0 & 0 \\
T3 Plagiocephaly & Total & $6(20.0 \%)$ & $6(17.6 \%)$ \\
& Mild & $6(20.0 \%)$ & $6(17.6 \%)$ \\
& Moderate & 0 & 0 \\
T4 Plagiocephaly & Severe & 0 & 0 \\
& Total & $4(12.5 \%)$ & $5(15.2 \%)$ \\
& Mild & $4(12.5 \%)$ & $5(15.2 \%)$ \\
& Moderate & 0 & 0 \\
& Severe & 0 & 0 \\
\hline
\end{tabular}

Table 4 describes the cranial parameters between the subgroups of VPT, MPT, and LPT infants. CI was smaller in the VPT group compared to the LPT group at T1 and T4. The median value of OCLR was significantly greater in the subgroup of LPT infants compared to MPT infants at T3-T4 (Table 4). 
Table 4. The median and range values for OCLR, CI, wAS, and FS at the study time points (T1-T4) in preterm subgroups.

\begin{tabular}{|c|c|c|c|c|c|c|c|c|c|c|c|}
\hline \multirow{3}{*}{ T1-T4 } & \multicolumn{7}{|c|}{ Parameters at Timepoints } & \multicolumn{4}{|c|}{ Kruskal-Wallis Post-Hoc Analysis } \\
\hline & \multirow{2}{*}{$\mathbf{n}$} & \multicolumn{2}{|c|}{ VPT } & \multicolumn{2}{|c|}{ MPT } & \multicolumn{2}{|c|}{ LPT } & \multirow[b]{2}{*}{$p$} & \multirow{2}{*}{$\begin{array}{c}\text { MPT-VPT } \\
p\end{array}$} & \multirow{2}{*}{$\begin{array}{c}\text { LPT-VPT } \\
p\end{array}$} & \multirow{2}{*}{$\begin{array}{c}\text { LPT-MPT } \\
p\end{array}$} \\
\hline & & Median & Range & Median & Range & Median & Range & & & & \\
\hline \multicolumn{12}{|l|}{ OCLR \% } \\
\hline $\mathrm{T} 1$ & $10 / 13 / 11$ & 102.3 & $101.1-104.2$ & 102.1 & $101.0-105.3$ & 105.8 & $102.5-108.7$ & 0.106 & - & - & - \\
\hline $\mathrm{T} 2$ & $8 / 13 / 11$ & 102.0 & $101.3-104.6$ & 101.7 & $100.7-103.1$ & 103.5 & $101.3-106.7$ & 0.262 & - & - & - \\
\hline $\mathrm{T} 3$ & $8 / 13 / 9$ & 102.0 & $101.2-104.0$ & 101.2 & $100.3-102.0$ & 102.9 & $102.1-106.3$ & 0.032 & 0.511 & 0.878 & 0.028 \\
\hline $\mathrm{T} 4$ & $10 / 12 / 10$ & 101.6 & $101.1-102.9$ & 101.1 & $100.7-102.5$ & 102.6 & $101.7-104.7$ & 0.046 & 1.000 & 0.199 & 0.051 \\
\hline \multicolumn{12}{|l|}{$\mathrm{CI} \%$} \\
\hline $\mathrm{T} 1$ & $10 / 13 / 11$ & 70.0 & $68.4-73.1$ & 73.0 & $72.5-77.3$ & 78.4 & $75.9-79.2$ & 0.003 & 0.115 & 0.002 & 0.404 \\
\hline $\mathrm{T} 2$ & 8/13/11 & 72.5 & $70.8-79.1$ & 75.4 & $73.5-79.0$ & 78.8 & $75.3-83.8$ & 0.052 & - & - & - \\
\hline $\mathrm{T} 3$ & 8/13/9 & 73.1 & $70.3-77.1$ & 75.6 & $72.5-79.0$ & 79.3 & $75.1-81.9$ & 0.061 & - & - & - \\
\hline $\mathrm{T} 4$ & $10 / 12 / 10$ & 73.4 & $71.0-76.6$ & 75.6 & $73.2-80.3$ & 77.9 & $76.0-80.6$ & 0.039 & 0.582 & 0.032 & 0.517 \\
\hline \multicolumn{12}{|l|}{ wAS } \\
\hline $\mathrm{T} 1$ & $10 / 13 / 11$ & 13.9 & $3.6-44.3$ & 8.8 & $3.4-30.4$ & 43.9 & $8.0-88.2$ & 0.076 & - & - & - \\
\hline $\mathrm{T} 2$ & 8/13/11 & 7.7 & $3.7-14.1$ & 8.8 & $2.7-17.5$ & 15.6 & $2.6-63.9$ & 0.649 & - & - & - \\
\hline $\mathrm{T} 3$ & 8/13/9 & 9.0 & $5.4-17.7$ & 9.4 & $2.5-15.0$ & 10.5 & $5.2-46.2$ & 0.477 & - & - & - \\
\hline $\mathrm{T} 4$ & $10 / 12 / 10$ & 4.6 & $2.4-13.8$ & 4.8 & $3.1-15.3$ & 24.2 & $16.6-45.1$ & 0.014 & 1.000 & 0.020 & 0.057 \\
\hline \multicolumn{12}{|l|}{ FS } \\
\hline $\mathrm{T} 1$ & $10 / 13 / 11$ & 0.218 & $0.209-0.227$ & 0.200 & $0.194-0.21$ & 0.216 & $0.196-0.228$ & 0.042 & 0.056 & 1.000 & 0.190 \\
\hline $\mathrm{T} 2$ & 8/13/11 & 0.225 & $0.209-0.231$ & 0.204 & $0.192-0.222$ & 0.219 & $0.193-0.229$ & 0.227 & - & - & - \\
\hline $\mathrm{T} 3$ & 8/13/9 & 0.202 & $0.193-0.218$ & 0.205 & $0.188-0.230$ & 0.204 & $0.193-0.214$ & 0.99 & - & - & - \\
\hline $\mathrm{T} 4$ & $10 / 12 / 10$ & 0.206 & $0.201-0.212$ & 0.195 & $0.187-0.226$ & 0.215 & $0.199-0.225$ & 0.428 & - & - & - \\
\hline
\end{tabular}

Of the preterm participants, 20 were born as nonsingletons and 14 as singletons. But in comparison, those did not differ statistically in the mean values of OCLR, CI, wAS, or FS. 


\section{Discussion}

This follow-up study characterizes the cranial growth features and the course of cranial symmetry and shape in preterm versus term born infants from early infancy to toddler age in the Finnish population. Our study is the first known longitudinal study using 3D imaging to examine the development of cranial shape and the natural course of DP in preterm children compared with full-term children up to the age of three years.

Data detailing the pattern of head growth of infants in this study were in accordance with previous data from large cohorts [26,27], and there were no statistically significant differences between groups in the weight, length, or head circumference after T1, where preterm infants were younger than term controls. Among both preterm and full-term children, the course of cranial asymmetry was equally favorable between T1 and T4; both the highest mean value of OCLR and the highest point prevalence for DP were observed at T1, with up to one-third of the children in both groups qualifying as having DP. Subsequently, the incidence of DP gradually diminished equally in both groups. The course of DP in full-term children follows a similar pattern worldwide, as our results are similar to other reports in various populations [5,28,29].

Understandably, the risk for developing DP is highest during the first months of life, when infants lie in the supine position most of the time and often have a preferential side for lateral head orientation [30]. Once infants are able to change the head position independently, the impact of external forces and pressure on the occiput rapidly decrease [5]. The head orientation profile of healthy full-term infants normally changes from lateral head orientation to midline orientation in three to nine weeks after birth, and a delay in that maturation seems to associate with DP [31]. Accordingly, head turn preference at TEA in preterm infants has been associated with DP, but also with the severity of medical comorbidities and poor neurobehavioral performance [19,32-34].

Somewhat surprisingly, LPT infants had considerably more cranial asymmetry in terms of both OCLR and wAS than earlier born preterm infants. In a cross-sectional study of preterm infants in TEA, Ifflaender et al. reported quite conversely that very preterm infants had statistically significantly more plagiocephaly compared to late preterm and term born infants [19]. Our study results are not, however, fully comparable with Ifflaender et al. because the observation period in our study started when the infants were three months old. Nevertheless, the prevalence of DP among VPT and MPT infants is far lower in this population at the ages of three and six months than has been reported in the literature $[33,35]$. These findings are likely explained by the fact that throughout their stay in the NICU, nursing staff members pay attention to varying each infant's position, usually changing it every 3-4 $\mathrm{h}$ according to treatments. Parents are also able to get the infants to kangaroo care on a daily basis. Additionally, parents get repeated guidance on infant handling and positioning from the nursing staff and from a specialized physiotherapist before discharge.

After discharge, all infants follow the regular Finnish well child visit schedule, including visits to a primary healthcare nurse on a monthly to bimonthly basis as well as to a primary healthcare physician at approximately two, four, and eight months of age. VPT infants additionally visit a pediatrician and a physiotherapist at three-month intervals. Advice on positioning and handling may be provided at any of these visits, and whenever necessary, physiotherapy may be commenced. None of the infants in this study received helmet therapy. It can be inferred that the systematic follow-up of the development of both preterm and term born infants in Finland may have a great impact on the prevention of both DP and particularly more severe forms of the condition.

Although the incidence of DP decreased throughout the whole observation period both in preterm and term groups, there was a notable amount of cranial asymmetry still present at the age of three years. The amount of residual cranial asymmetry at the age of three in this study is analogous with an earlier European study [5]. It is known that DP may take a long time to resolve [28,36], and sometimes it may be permanent, as Ruby et al. report the prevalence of deformational cranial abnormalities to be $2 \%$ in teens born after the 'Back to Sleep' campaign [36]. Furthermore, although DP is usually transient, it may be associated with delayed motor development or torticollis [11,13,33,34]. DP also associates with a rotation of the cranial base and the anterior displacement of the articular fossa on the 
affected side, which is hypothesized to cause facial asymmetry [37-39]. To prevent and to detect these later consequences of DP, a systematic follow-up combined with proactive advice for infant handling, especially during NICU care, might be useful, particularly for preterm infants.

The early-born preterm infants in this study had a more dolichocephalic skull shape than late-born preterm infants. A similar finding was reported by Ifflaender et al. [19], who also observed that among preterm children, $\mathrm{CI}$ increased from discharge to the age of three months and further to the age of six months [35]. In our study population, a similar increase in CI from T1 to T2 in every subgroup was observed, whereafter there was a slightly decreasing trend toward T4 (Figure 2). Generally, both Finnish preterm and term born infants and toddlers have more dolichocephalic skull shapes than what has been reported from other populations $[26,29,35,40]$, which might be either purely ethnic or a generational phenomenon [14].

Despite being more dolichocephalic, the preterm children had more symmetrical occipital flatness than term ones, as indicated by FS values (Figure 1). Hence, it appears that the particularly malleable skullcap of preterms not only tends to narrow bilaterally but also flattens occipitally more than the cranium of term infants. This finding further highlights the importance of preventive and positioning advice at an early age [7], especially with preterm infants, in order to direct the growth of the cranium to the symmetric direction.

The strengths of this study include its prospective setting; a long follow-up time up to three years of age; its randomly-selected, full-term control peers; and the use of 3D imaging, which brings systematism, consistency, and objectivity to analysis [11,40-42]. However, the use of the stereophotogrammetry method requires subjects to support their head in the upright position during imaging. Therefore stereophotogrammetry is not the proper method for studying infants at TEA or other time points in early life. For this reason, the time interval to follow cranial molding from three months to three years was chosen, which might be considered a weakness. However, this period includes the peak prevalence of DP, and during this period, the majority of spontaneous resolving of cranial asymmetry is expected to happen $[8,43]$. Also, the differences in cranial shape and symmetry between preterm and full-term born children in TEA has been documented earlier [19].

The small number of subjects in the preterm subgroups is a limitation of this study. Nevertheless, the sample size was considered adequate for comparing cranial molding and the course of cranial asymmetry between preterm and full-term children, which was the main aim of this study. A final limitation is that unlike the case of plagiocephaly, there are no established cut-off values for dolichocephaly or brachycephaly, and cut-off values used in previous studies vary widely $[5,19,44,45]$. Thus, comparing the incidence of dolichocephaly or brachycephaly is problematic between different studies and populations. Because of that, we decided to report and discuss only the absolute values for the cephalic index.

Even though it appears that parental guidance and the attention paid to infant positioning in specialized care might prevent plagiocephaly, no reliable conclusions cannot be drawn from this study as it was not designed to test this hypothesis. Therefore, future research should focus on the effect of DP prevention among preterm born infants in NICU. Also, there is still a lack of information about the later consequences of DP, especially its effects on the facial asymmetry or occlusal disorders later in life.

\section{Conclusions}

In this study, DP was found to affect preterm and full-term children almost equally during the first three years of life, and cranial asymmetry resolved at a similar rate in both preterm and term born children after three months of corrected age. The average cranial shape among Finnish children is relatively dolichocephalic. Very preterm born infants have a more dolichocephalic skull shape than late preterm, but despite this, preterm infants present with more occipital flattening than full-term children.

Author Contributions: Conceptualization, T.H., P.P., V.H. and A.M.V.; methodology, H.A., V.V., and A.M.V.; software, V.V.; validation, V.V. and H.A.; formal analysis, A.M.L., V.V., and A.M.V.; investigation, A.M.L., H.A., V.V., T.H., P.P., V.H., and A.M.V.; resources, P.P. and A.M.V.; data curation, H.A., V.V., and A.M.V.; writing-original draft preparation, A.M.L., H.A., P.K., and A.M.V.; writing-review and editing, V.V., T.H., C.H.K., P.P., and V.H.; visualization, A.M.L.; supervision, C.H.K., P.P., V.H., and A.M.V.; project administration, A.M.V.; funding acquisition, P.P. and A.M.V. 
Funding: This research was funded by The University of Oulu Scholarship Foundation, the Orthodontic Section of the Finnish Dental Association Apollonia, the Emil Aaltonen Foundation, the Alma, and K.A. Snellman Foundation, the Finnish Medical Foundation, and the Foundation for Pediatric Research in Finland.

Acknowledgments: We are grateful to all the children and their families who participated in the study.

Conflicts of Interest: The authors declare no conflicts of interest. The funders had no role in the design of the study; in the collection, analyses, or interpretation of data; in the writing of the manuscript; or in the decision to publish the results.

\section{References}

1. American Academy of Pediatrics AAP. Task Force on Infant Positioning and SIDS: Positioning and SIDS. Pediatrics 1992, 89, 1120-1126.

2. Mawji, A.; Vollman, A.R.; Hatfield, J.; McNeil, D.A.; Sauvé, R. The Incidence of Positional Plagiocephaly: A Cohort Study. Pediatrics 2013, 132, 298-304. [CrossRef] [PubMed]

3. Mawji, A.; Vollman, A.R.; Fung, T.; Hatfield, J.; McNeil, D.A.; Sauvé, R. Risk factors for positional plagiocephaly and appropriate time frames for prevention messaging. Paediatr. Child Health 2014, 19, $423-427$. [CrossRef] [PubMed]

4. Van Vlimmeren, L.A.; Takken, T.; Van Adrichem, L.N.; Van Der Graaf, Y.; Helders, P.J.; Engelbert, R.H. Plagiocephalometry: A non-invasive method to quantify asymmetry of the skull; a reliability study. Eur. J. Pediatr. 2006, 165, 149-157. [CrossRef] [PubMed]

5. Van Vlimmeren, L.A.; Engelbert, R.H.; Pelsma, M.; Groenewoud, H.M.; Boere-Boonekamp, M.M.; Nijhuis-van der Sanden, M.W. The course of skull deformation from birth to 5 years of age: A prospective cohort study. Eur. J. Pediatr. 2017, 176, 11-21. [CrossRef] [PubMed]

6. Meyer-Marcotty, P.; Böhm, H.; Linz, C.; Kochel, J.; Blecher, C.; Keil, N.; Stellzig-Eisenhauer, A.; Schweitzer, T. Spectrum of positional deformities-Is there a real difference between plagiocephaly and brachycephaly? J. Cranio-Maxillofac. Surg. 2014, 42, 1010-1016. [CrossRef] [PubMed]

7. Aarnivala, H.; Vuollo, V.; Harila, V.; Heikkinen, T.; Pirttiniemi, P.; Valkama, A. Preventing deformational plagiocephaly through parent guidance: A randomized, controlled trial. Eur. J. Pediatr. 2015, 174, 1197-1208. [CrossRef] [PubMed]

8. Aarnivala, H.; Vuollo, V.; Harila, V.; Heikkinen, T.; Pirttiniemi, P.; Holmström, L.; Valkama, A. The course of positional cranial deformation from 3 to 12 months of age and associated risk factors: A follow-up with 3D imaging. Eur. J. Pediatr. 2016, 175, 1893-1903. [CrossRef]

9. De Bock, F.; Braun, V.; Renz-Polster, H. Deformational plagiocephaly in normal infants: A systematic review of causes and hypotheses. Arch. Dis. Child. 2017, 102, 535-542. [CrossRef]

10. Ballardini, E.; Sisti, M.; Basaglia, N.; Benedetto, M.; Baldan, A.; Borgna-Pignatti, C.; Garani, G. Prevalence and characteristics of positional plagiocephaly in healthy full-term infants at 8-12 weeks of life. Eur. J. Pediatr. 2018, 177, 1547-1554. [CrossRef]

11. Linz, C.; Kunz, F.; Böhm, H.; Schweitzer, T. Positional Skull Deformities: Etiology, Prevention, Diagnosis, and Treatment. Dtsch. Arztebl. Int. 2017, 114, 535-542. [CrossRef] [PubMed]

12. Argenta, L.; David, L.; Thompson, J. Clinical Classification of Positional Plagiocephaly. J. Craniofac. Surg. 2004, 15, 368-372. [CrossRef] [PubMed]

13. Rogers, G.F. Deformational plagiocephaly, brachycephaly, and scaphocephaly. Part I: Terminology, diagnosis, and etiopathogenesis. J. Craniofac. Surg. 2011, 22, 9-16. [CrossRef] [PubMed]

14. Looman, W.S.; Flannery, A.B. Evidence-Based Care of the Child With Deformational Plagiocephaly, Part I: Assessment and Diagnosis. J. Pediatr. Health Care 2012, 26, 242-250. [CrossRef] [PubMed]

15. Flannery, A.B.K.; Looman, W.S.; Kemper, K. Evidence-based care of the child with deformational plagiocephaly, part II: Management. J. Pediatr. Health Care 2012, 26, 320-331. [CrossRef] [PubMed]

16. Branch, L.G.; Kesty, K.; Krebs, E.; Wright, L.; Leger, S.; David, L.R. Argenta Clinical Classification of Deformational Plagiocephaly. J. Craniofac. Surg. 2015, 26, 606-610. [CrossRef] [PubMed]

17. Bruneteau, R.J.; Mulliken, J.B. Frontal Plagiocephaly: Synostotic, Compensational, or Deformational. Plast. Reconstr. Surg. 1992, 89, 21-31. [CrossRef] 
18. Mewes, A.U.J.; Zöllei, L.; Hüppi, P.S.; Als, H.; McAnulty, G.B.; Inder, T.E.; Wells, W.M.; Warfield, S.K. Displacement of brain regions in preterm infants with non-synostotic dolichocephaly investigated by MRI. Neuroimage 2007, 36, 1074-1085. [CrossRef]

19. Ifflaender, S.; Rüdiger, M.; Konstantelos, D.; Wahls, K.; Burkhardt, W. Prevalence of head deformities in preterm infants at term equivalent age. Early Hum. Dev. 2013, 89, 1041-1047. [CrossRef]

20. Geerdink, J.J.; Hopkins, B.; Hoeksma, J.B. The development of head position preference in preterm infants beyond term age. Dev. Psychobiol. 1994, 27, 153-168. [CrossRef]

21. Chan, J.S.; Kelley, M.L.; Khan, J. Predictors of postnatal head molding in very low birth weight infants. Neonatal Netw. 1995, 14, 47-51. [PubMed]

22. Lennartsson, F.; Nordin, P. Nonsynostotic plagiocephaly: A child health care intervention in Skaraborg, Sweden. BMC Pediatr. 2019, 19, 48. [CrossRef] [PubMed]

23. Leung, A.; Mandrusiak, A.; Watter, P.; Gavranich, J.; Johnston, L.M. Impact of Parent Practices of Infant Positioning on Head Orientation Profile and Development of Positional Plagiocephaly in Healthy Term Infants. Phys. Occup. Ther. Pediatr. 2018, 38, 1-14. [CrossRef] [PubMed]

24. Vuollo, V.; Holmström, L.; Aarnivala, H.; Harila, V.; Heikkinen, T.; Pirttiniemi, P.; Valkama, A.M. Analyzing infant head flatness and asymmetry using kernel density estimation of directional surface data from a craniofacial 3D model. Stat. Med. 2016, 35, 4891-4904. [CrossRef] [PubMed]

25. Aarnivala, H.; Vuollo, V.; Heikkinen, T.; Harila, V.; Holmström, L.; Pirttiniemi, P.; Valkama, A.M. Accuracy of measurements used to quantify cranial asymmetry in deformational plagiocephaly. J. Craniomaxillofac. Surg. 2017, 45, 1349-1356. [CrossRef] [PubMed]

26. Meyer-Marcotty, P.; Kunz, F.; Schweitzer, T.; Wachter, B.; Böhm, H.; Waßmuth, N.; Linz, C. Cranial growth in infants-A longitudinal three-dimensional analysis of the first months of life. J. Cranio-Maxillofac. Surg. 2018, 46, 987-993. [CrossRef]

27. Saari, A.; Sankilampi, U.; Hannila, M.; Kiviniemi, V.; Kesseli, K.; Dunkel, L. New Finnish growth references for children and adolescents aged 0 to 20 years: Length/height-for-age, weight-for-length/height, and body mass index-for-age. Ann. Med. 2011, 43, 235-248. [CrossRef] [PubMed]

28. Collett, B.R.; Heike, C.L.; Atmosukarto, I.; Starr, J.R.; Cunningham, M.L.; Speltz, M.L. Longitudinal, three-dimensional analysis of head shape in children with and without deformational plagiocephaly or brachycephaly. J. Pediatr. 2012, 160, 673-678. [CrossRef] [PubMed]

29. Hutchison, B.L.; Hutchison, L.A.D.; Thompson, J.M.D.; Mitchell, E.A. Plagiocephaly and Brachycephaly in the First Two Years of Life: A Prospective Cohort Study. Pediatrics 2004, 114, 970-980. [CrossRef]

30. Boere-Boonekamp, M.M.; van der Linden-Kuiper, L.T. Positional Preference: Prevalence in Infants and Follow-Up After Two Years. Pediatrics 2001, 107, 339-343. [CrossRef]

31. Leung, A.Y.F.; Mandrusiak, A.; Watter, P.; Gavranich, J.; Johnston, L.M. Clinical assessment of head orientation profile development and its relationship with positional plagiocephaly in healthy term infants-A prospective study. Early Hum. Dev. 2016, 96, 31-38. [CrossRef] [PubMed]

32. Nuysink, J.; van Haastert, I.C.; Eijsermans, M.J.C.; Koopman-Esseboom, C.; van der Net, J.; de Vries, L.S.; Helders, P.J.M. Prevalence and predictors of idiopathic asymmetry in infants born preterm. Early Hum. Dev. 2012, 88, 387-392. [CrossRef] [PubMed]

33. Nuysink, J.; Eijsermans, M.J.C.; van Haastert, I.C.; Koopman-Esseboom, C.; Helders, P.J.M.; de Vries, L.S.; van der Net, J. Clinical course of asymmetric motor performance and deformational plagiocephaly in very preterm infants. J. Pediatr. 2013, 163, 658-665. [CrossRef] [PubMed]

34. Dunsirn, S.; Smyser, C.; Liao, S.; Inder, T.; Pineda, R. Defining the nature and implications of head turn preference in the preterm infant. Early Hum. Dev. 2016, 96, 53-60. [CrossRef] [PubMed]

35. Ifflaender, S.; Rüdiger, M.; Konstantelos, D.; Lange, U.; Burkhardt, W. Individual course of cranial symmetry and proportion in preterm infants up to 6 months of corrected age. Early Hum. Dev. 2014, 90, 511-515. [CrossRef] [PubMed]

36. Roby, B.B.; Finkelstein, M.; Tibesar, R.J.; Sidman, J.D. Prevalence of positional plagiocephaly in teens born after the "Back to Sleep" campaign. Otolaryngol. Head Neck Surg. 2012, 146, 823-828. [CrossRef] [PubMed]

37. John, D.S.; Mulliken, J.B.; Kaban, L.B.; Padwa, B.L. Anthropometric analysis of mandibular asymmetry in infants with deformational posterior plagiocephaly. J. Oral Maxillofac. Surg. 2002, 60, 873-877. [CrossRef] 
38. Smartt, J.; James, M.; Elliott, R.M.; Reid, R.R.; Bartlett, S.P. Analysis of Differences in the Cranial Base and Facial Skeleton of Patients with Lambdoid Synostosis and Deformational Plagiocephaly. Plast. Reconstr. Surg. 2011, 127, 303-312. [CrossRef]

39. Moon, I.Y.; Lim, S.Y.; Oh, K.S. Analysis of Facial Asymmetry in Deformational Plagiocephaly Using Three-Dimensional Computed Tomographic Review. Arch. Craniofac. Surg. 2014, 15, 109-116. [CrossRef]

40. Meyer-Marcotty, P.; Bohm, H.; Linz, C.; Kochel, J.; Stellzig-Eisenhauer, A.; Schweitzer, T. Three-dimensional analysis of cranial growth from 6 to 12 months of age. Eur. J. Orthod. 2014, 36, 489-496. [CrossRef]

41. Schaaf, H.; Pons-Kuehnemann, J.; Malik, C.Y.; Streckbein, P.; Preuss, M.; Howaldt, H.P.; Wilbrand, J.F. Accuracy of Three-Dimensional Photogrammetric Images in Non-Synostotic Cranial Deformities. Neuropediatrics 2010, 41, 24-29. [CrossRef] [PubMed]

42. Skolnick, G.B.; Naidoo, S.D.; Nguyen, D.C.; Patel, K.B.; Woo, A.S. Comparison of Direct and Digital Measures of Cranial Vault Asymmetry for Assessment of Plagiocephaly. J. Craniofac. Surg. 2015, 26, 1900-1903. [CrossRef]

43. Bialocerkowski, A.E.; Vladusic, S.L.; Wei Ng, C. Prevalence, risk factors, and natural history of positional plagiocephaly: A systematic review. Dev. Med. Child Neurol. 2008, 50, 577-586. [CrossRef] [PubMed]

44. Wilbrand, J.; Schmidtberg, K.; Bierther, U.; Streckbein, P.; Pons-Kuehnemann, J.; Christophis, P.; Hahn, A.; Schaaf, H.; Howaldt, H. Clinical classification of infant nonsynostotic cranial deformity. J. Pediatr. 2012, 161, 1120-1125. [CrossRef] [PubMed]

45. Hutchison, B.L.; Hutchison, L.A.D.; Thompson, J.M.D.; Mitchell, E.A. Quantification of Plagiocephaly and Brachycephaly in Infants Using a Digital Photographic Technique. Cleft Palate Craniofac. J. 2005, 42, 539-547. [CrossRef] [PubMed]

(C) 2019 by the authors. Licensee MDPI, Basel, Switzerland. This article is an open access article distributed under the terms and conditions of the Creative Commons Attribution (CC BY) license (http://creativecommons.org/licenses/by/4.0/). 